\title{
Use of Reclaimed Asphalt Pavement in Conjunction with Ground Improvement: A Case History
}

\author{
Kevin C. Foye \\ CTI and Associates Inc., 51331 W. Pontiac Trail, Wixom, MI 48393, USA \\ Correspondence should be addressed to Kevin C. Foye, kfoye@cticompanies.com \\ Received 2 February 2011; Accepted 17 May 2011 \\ Academic Editor: Paola Bandini \\ Copyright () 2011 Kevin C. Foye. This is an open access article distributed under the Creative Commons Attribution License, \\ which permits unrestricted use, distribution, and reproduction in any medium, provided the original work is properly cited. \\ The use of Reclaimed Asphalt Pavement (RAP) in lieu of virgin crushed stone aggregate is becoming a widely accepted practice for \\ a number of construction applications, particularly pavement base courses. A number of laboratory RAP studies have considered \\ the mechanical properties of RAP bases in order to support pavement designs incorporating RAP. These studies have revealed a \\ number of interesting relationships between RAP moisture content, compaction, and stiffness. This paper discusses the experiences \\ of a design-build contractor integrating a geosynthetic ground improvement program with a RAP base during the reconstruction \\ of a 1.95 ha asphalt parking lot. Field observations of base course construction with RAP explore some of the implications of \\ laboratory findings. A number of interesting observations on the technical, construction, and economic issues resulting from the \\ project challenges and the use of RAP are presented.
}

\section{Introduction}

The use of Reclaimed Asphalt Pavement (RAP) in lieu of virgin crushed stone aggregate is becoming a widely accepted practice for a number of construction applications, particularly pavement base courses, as evidenced by its inclusion in department of transportation specifications, including Minnesota Department of Transportation (Mn/DOT) [1]. The use of RAP in this application is attractive for a number of reasons: first, it reduces the cost of material production by eliminating quarrying, crushing, and screening operations. Second, for repaving projects, it reduces handling and transportation costs since the RAP is retained onsite for reuse. Third, it reduces the consumption of natural resources and energy, as reflected in the reduced costs in the first two points.

Engineers designing pavements require reliable design guidance to incorporate any material into their design pavement sections. Common flexible pavement design methodologies are largely calibrated to empirical studies while their formulation is informed by commonly measured mechanical properties, especially resilient modulus and various measurements that correlate with resilient modulus
(Puppala [2], AASHTO [3]). Hence, studies to support the incorporation of RAP into pavement designs have focused on characterizing its mechanical properties. The mechanical properties of RAP are expected to largely mimic those of crushed stone aggregate due to its similar compositionwith the notable exception of residual asphalt binder-and particle-size gradation. Several authors, including Attia and Abdelrahman [4], Mokwa and Peebles [5], and Locander [6] have performed laboratory studies of RAP, focusing on tests of interest to pavement base construction, including Proctor compaction, California Bearing Ratio (CBR), and resilient modulus. The goal of these studies has been to assess the suitability of RAP as a base course material and to offer design guidance to engineers designing pavement sections including RAP.

The contribution of this paper is to share some anecdotal observations regarding the use of RAP to construct the base course of a flexible pavement system. The project presented involved the reclamation and repavement of exist-ing distressed asphalt pavement over a soft subgrade. Field observations regarding the behavior and preparation of RAP not only confirm a number of laboratory observations, but also provide some answers to lingering questions from 


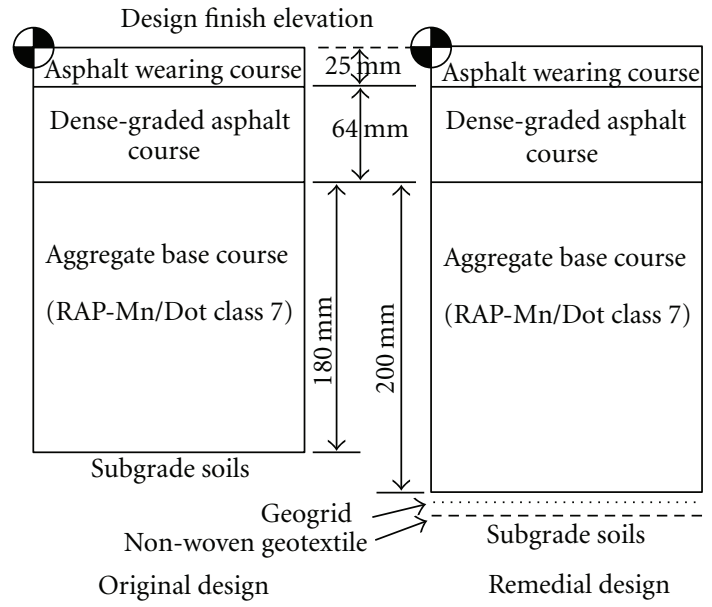

FIGURE 1: Design pavement cross sections.

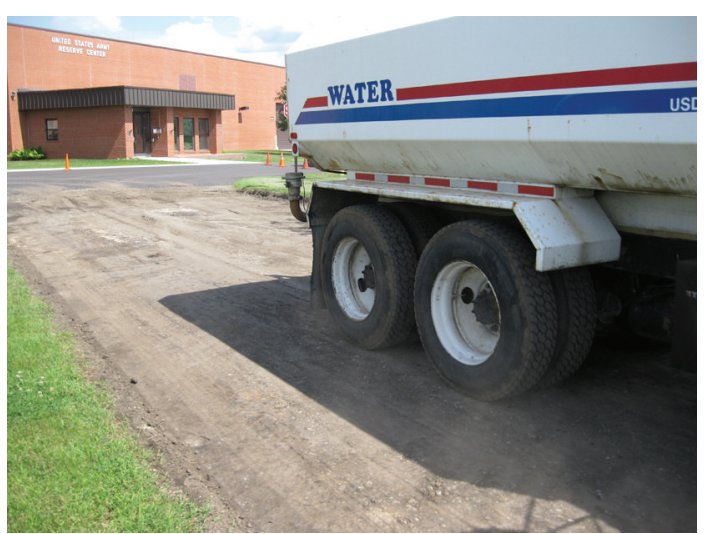

FIgURe 2: Photo showing typical proof rolling test. the laboratory studies-especially the question of whether or not RAP offers comparable performance to crushed stone aggregate as a base course. Additionally, due to a discovered subgrade problem at the project site, engineers also integrated the planned RAP base into a remedial solution to avoid a costly subgrade replacement. Hence this paper also shares the experiences of the prime contractor integrating a geosynthetic ground improvement program with the RAP recycling. A number of interesting observations on the technical, construction, and economic issues resulting from the project challenges and the use of RAP are presented.

\section{Project Background}

The project was to rehabilitate a $19,500 \mathrm{~m}^{2}$ (1.95 ha) asphalt parking lot within the US Army Reserve Facility (owner), Fort Snelling, Minn, USA under the direction of personnel from the US Army Corps of Engineers (USACE), Kansas City, and St. Paul Districts. The parking lot is used to park a number of light- and heavy-duty rubber-tired and tracked vehicles. The existing, 30-year-old parking lot pavement had several low points that did not drain properly, resulting in ponding, moisture damage, and severe alligator cracking to the point of pot holes and loose aggregate. The prime contractor, which includes the author, was responsible for construction of the planned rehabilitation according to design plans and specifications prepared by the USACE's consulting engineer. This responsibility was expanded to include design-build and value engineering services as a result of conditions encountered during the project. Rehabilitation included improving site drainage through regrading, installation of new stormwater collection structures, and construction of new stormwater discharge control features. The existing, distressed asphalt pavement was milled and stockpiled for reuse as RAP in the new pavement base course. The design pavement cross section is shown in Figure 1 as "Original Design." This section was selected by the USACE's consulting engineer because it exactly replaced the existing pavement section: $75-100 \mathrm{~mm}$ of asphalt pavement over
175-200 $\mathrm{mm}$ of base aggregate. The existing pavement section was determined by soil borings through the parking lot.

Suitability of the subgrade to support the pavement system was assessed by means of a proof rolling test, whereby a loaded rubber-tired water truck is driven over the subgrade and a quality control technician observes the subgrade for signs of deflection, pumping, and/or rutting under the action of the tires (Figure 2). Observed pumping and rutting disqualifies the subgrade. Areas of disqualified subgrade required either compaction or replacement to meet design requirements. In cases where compaction is ineffective in achieving an acceptable subgrade, the contract required the undercutting of the subgrade to a depth of $1 \mathrm{~m}$ below top of subgrade elevation and replacement with compacted imported fill.

Following milling of the existing pavement and removal of the existing base material, the paving subcontractor proof rolled the existing subgrade. The quality control technician noted significant deflection, pumping, and rutting of the subgrade during proof rolling, suggesting that the subgrade may be unsuitable to depths greater than 300 to $1000 \mathrm{~mm}$. Consequently, the subgrade was deemed unsuitable for placement of the pavement base. The extent of the permanent rutting, partially shown in Figure 3, indicated that nearly all of the 1.95 ha parking lot subgrade would require improvement.

To further investigate the subsurface profile following the failed proof-roll tests, the prime contractor excavated several test pits into the parking lot subgrade. These test pits revealed the consistent expression of a wet organic silt layer throughout the parking lot footprint. Figure 4 presents a photo of a typical test pit showing the organic silt layer. The organic silt varied in thickness over the site from 300 to $600 \mathrm{~mm}$. A layer of wet, silty sand immediately below the organic silt also appeared to contribute to the poor condition of the subgrade and may also be responsible for the observed pumping during proof-roll testing. The typical depth to the bottom of the wet silt is $1 \mathrm{~m}$ below the top of subgrade.

Laboratory testing of the subsurface soils included grain size distribution and Atterberg Limits. Table 1 summarizes the results of the laboratory classification testing. Atterberg 


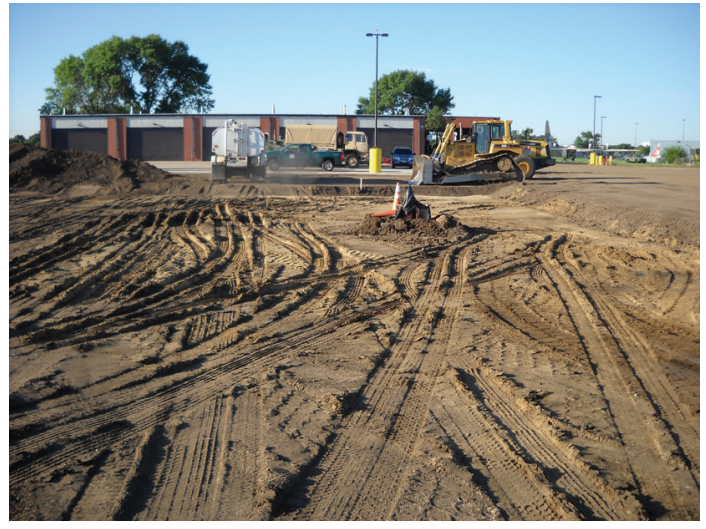

FIGURe 3: Photo showing typical rutting observed following proof rolling of the existing subgrade.

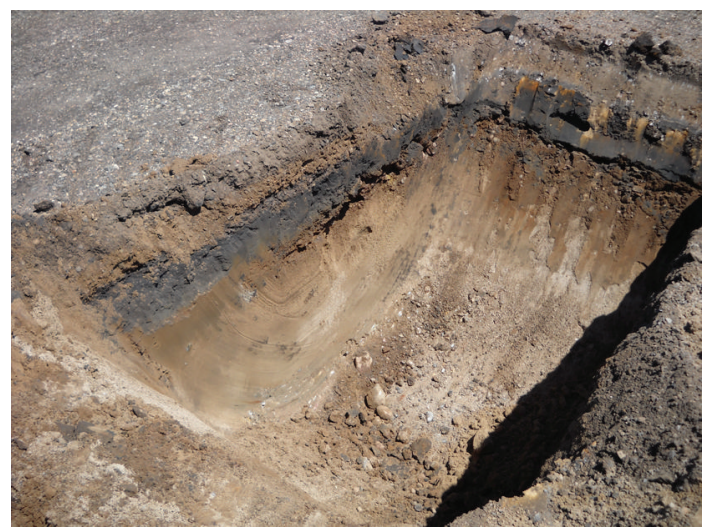

FIGURE 4: Example test pit showing, from top to bottom, typical soil profile: residual gray base aggregate, brown silty sand, black organic silt, brown silty sand.

limits were determined for both air-dried and oven-dried samples to assess the potential influence of organic materials. These tests confirmed that the black silt layer classifies as an organic soil. Field testing included the aforementioned proof rolling and Dynamic Cone Penetrometer (DCP) sounding (ASTM D6951 [7]). DCP soundings revealed DCP indices from $<15 \mathrm{~mm} /$ blow to $90 \mathrm{~mm} / \mathrm{blow}$, indicating interpreted CBR values from 1 to $>10$. Representative values of CBR assessed for the subgrade were between 1 and 3 .

Adherence to the project specifications would have required excavation and replacement of the subgrade to a depth of $1 \mathrm{~m}$ over the entire 1.95 ha site, resulting in about $19,500 \mathrm{~m}^{3}$ of additional spoil and imported fill. The prime contractor considered this approach unnecessarily wasteful. Furthermore, the cost to perform this cut and replace improvement was prohibitive to the owner. Therefore, the prime contractor conducted a value engineering assessment of alternative options to address this issue at a significantly lower cost while achieving the performance required for the new pavement.
TABLE 1: Laboratory subgrade classification test results.

\begin{tabular}{lcccc}
\hline & \multicolumn{4}{c}{ Atterberg limits } \\
& Air-dried & \multicolumn{2}{c}{ Oven-dried } \\
Soil description & LL & PL & LL & PL \\
\hline Brown to brownish gray silt & 26 & 21 & 21 & 19 \\
Dark brown to black organic silt* & 26 & 16 & 18 & 16
\end{tabular}

* Note: the dark brown to black organic silt was classified as an organic silt since the liquid limit of the oven-dried sample was less than $75 \%$ of the liquid limit of the air-dried sample per ASTM D2488.

\section{Ground Improvement Approach}

Two viable alternative technologies were identified: (1) soil stabilization/modification and (2) geosynthetic reinforcement. For soil stabilization/modification, the prime contractor considered mixing the subgrade with lime, fly ash, or Portland cement. For geosynthetic reinforcement, the prime contractor considered installing a single layer of highstrength geotextile or geogrid reinforcement in combination with a geotextile separator. Because the prime contractor's engineers recognized the relatively high cost of the cut and replace alternative and the need for an effective improvement option, they adopted the "design by cost" methodology described by Koerner [8] in the sense that the selected alternative was designed to appeal to the owner in terms of cost while the technical evaluation satisfied conservative criteria for performance. Accordingly, preliminary estimates suggested that the geogrid/geotextile option would provide the best fit in terms of cost and performance.

Evaluation of the required pavement section using a triaxial geogrid layer as reinforcement was conducted using the methodology of AASHTO [3] in combination with improvement factors recommended by the geogrid manufacturer. Table 2 summarizes the AASHTO [3] layer coefficients assumed in the analysis of the design cross sections. The design $80-\mathrm{kN}$ Equivalent Single-Axle Load (ESAL) traffic was back calculated by taking as input the layer coefficients shown in Table 2, the original design asphalt and base course thicknesses, and a subgrade resilient modulus $=83 \mathrm{MPa}$. This value of resilient modulus was implied by the subgrade acceptance specifications. The remedial design cross section was selected to deliver equal or greater performance for the same number of ESALs as the original design assuming an actual subgrade resilient modulus $=27 \mathrm{MPa}(\mathrm{CBR} \approx 3)$. The resulting design cross section is shown in Figure 1 as "Remedial Design." The geotextile specified for the separator is a $271 \mathrm{~g} / \mathrm{m}^{2}$ needle-punched nonwoven geotextile. The function of the geotextile is to prevent the intrusion of subgrade silt into the overlying base course, ensuring proper interlock of the base aggregate and geogrid. Both the original design and the remedial design analyses considered $\mathrm{Mn} / \mathrm{DOT}$ class 5 stone aggregate base. The significance of the class 5 aggregate base is discussed in the following sections.

A cost estimate investigation of the stabilization/modification option revealed that a soil improvement cost comparable to the installation of the geotextile and geogrid could only be achieved by reducing the depth of improvement to $380 \mathrm{~mm}$ and by changing the soil additive to circulating 
TAble 2: Summary of AASHTO [3] Design Inputs Used to Analyze Pavement Sections. Original design value for resilient modulus was inferred from project specifications. Design ESALs were back calculated from original design pavement section.

\begin{tabular}{lcc}
\hline Design Parameter & Original Design Value & Remedial Design Value \\
\hline Asphalt Wearing Course Layer Coefficient & 0.42 & 0.42 \\
Dense-Graded Asphalt Course Layer Coefficient & 0.40 & 0.40 \\
Aggregate Base Course Layer Coefficient & 0.14 & 0.24 \\
Subgrade Resilient Modulus & $83 \mathrm{MPa}$ & $27 \mathrm{MPa}$ \\
Target Design ESALs & 176,000 & 176,000 \\
\hline
\end{tabular}

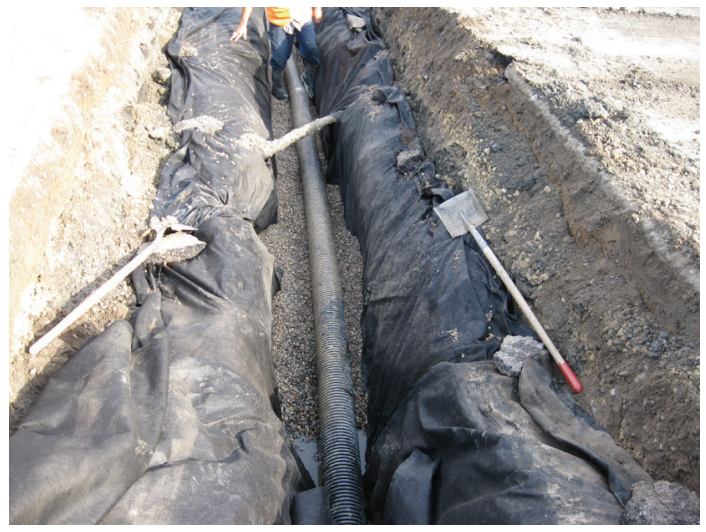

FIgURE 5: Photo showing installation of underdrains.

fluidized-bed (CFB) ash at a mixing ratio of $5 \%$ by weight. Due to these constraints, the prime contractor decided to abandon the soil stabilization/modification option for the following reasons: (1) limited time was available to conduct the necessary bench-scale testing of the candidate material: (2) if testing determined that a greater mixing ratio or more potent cementing agent were required, the soil stabilization/modification option would be disadvantaged in terms of cost.

\section{Implementation of Selected Ground Improvement Method}

As part of the original design, the prime contractor installed a number of underdrains extending from the recently installed catch basins. These underdrains consisted of a perforated high-density polyethylene (HDPE) pipe embedded in a stone aggregate-filled trench wrapped in a filter geotextile (Figure 5). The trenches were excavated about $700 \mathrm{~mm}$ deep into the subgrade. The effective area drained by these underdrains was limited to less than $10 \%$ of the total parking lot. However, their placement at the low points of the regraded parking lot subgrade may facilitate effective drainage of a much larger fraction of the total area. These drains became significant to the improvement of the subgrade due to concerns about the discovery of water trapped within the silty sand above the organic silt layer. The quality control technician noted that visible flow through the installed drains stopped within 4 to 5 hours of installation. Anecdotal accounts of improved subgrade conditions 2 months after the installation of the underdrains suggest that the drains contributed to the subgrade improvement.

After about 2 months of review, and consideration, the owner agreed to the recommended geogrid reinforcement option and construction resumed with the excavation of additional subgrade soil to accommodate the increased pavement section thickness. The geotextile and geogrid were unrolled directly onto the subgrade. Continuity of the geotextile with adjacent rolls was provided by a 900$\mathrm{mm}$ overlap. The geogrid panels were similarly joined by a 900-mm overlap only. Plastic cable ties were used to aid laborers deploying geogrid by temporarily securing panels together. The 900-mm overlap was recommended by the manufacturer for subgrades with CBR values less than 2 .

Following placement of the geotextile and geogrid, bulldozers were used to push the RAP base material onto the geogrid, taking care not to track over areas with less than $150 \mathrm{~mm}$ of RAP in place or to make sharp turns, which could damage or displace the geogrid. The base course was compacted with vibratory roller compactors. Quality control acceptance of the compacted RAP base course was based on DCP and proof roll testing. According to $2005 \mathrm{Mn} / \mathrm{DOT}$ specification (a modified version of the recommendations by Siekmeier et al. [9]), a DCP index of $10 \mathrm{~mm} / \mathrm{blow}$ or less was required to accept the base course compaction. The paving subcontractor applied additional compactive efforts to failing areas until they passed. Proof rolling was conducted on the base course in response to concerns raised by the asphalt paving subcontractor. Because the subcontractor was not involved in the decision to use geosynthetic reinforcement instead of excavating the subgrade-a considerable change in work-the subcontractor was unconvinced that the geogrid-reinforced RAP could provide a sufficient base atop the soft subgrade. Hence, additional reassurance was provided via proof rolling. Per agreed acceptance criteria, any areas exhibiting rutting during proof rolling were subject to additional compaction. Areas exhibiting no rutting, but visually perceptible deflection, were noted on the site plan for possible warranty relief. The prime contractor agreed to relieve the paving subcontractor of its warranty obligations for these areas if all other measures of workmanship (e.g., asphalt thickness and density) passed design criteria. This arrangement was agreed on because the paving subcontractor was not involved in the ground improvement decision and, therefore, felt it should not be subject to the risk assumed by the pursuit of the less expensive ground improvement alternative. 


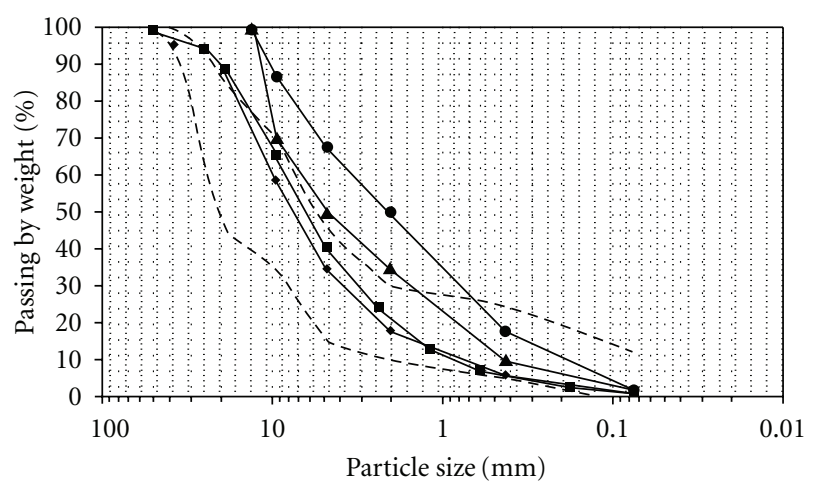

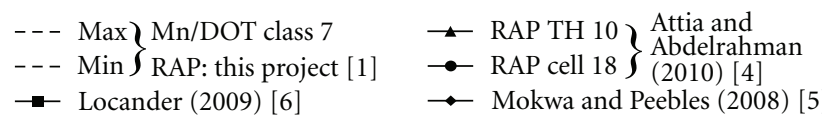

Figure 6: Comparison of Minnesota Department of Transportation (Mn/DOT) class 7 Particle Size Gradation Specification (RAP Used in This project) with Tested RAP Gradations from Selected Studies.

\section{RAP Base Suitability: Comparison of Laboratory Studies to Construction Observations}

Due to the intense interest in the reuse of RAP, many state and federal research agencies have encouraged the study of the mechanical properties of RAP when used as a base layer material. Accordingly, many authors have published the findings of RAP studies for this application. As with other recycled materials, studies have contemplated the use of RAP both alone and as a component of blended mixtures with stone aggregate manufactured from virgin sources. This paper considers the findings of few authors to compare laboratory observations to field observations of RAP behavior during construction.

Attia and Abdelrahman [4], Mokwa and Peebles [5], and Locander [6] investigated the strength and stiffness properties of RAP and RAP/stone aggregate blends in the laboratory to assess their suitability as pavement base layers. Since gradation is expected to have a significant effect on the behavior of RAP, it is useful to consider if the gradation of the RAP used in this project is comparable to these laboratory studies. The RAP used in this project met the criteria for Mn/DOT class 7 aggregate. Figure 6 plots the particle size gradation bounds for class 7 aggregate together with the gradation curves for the 100\% RAP aggregate tested by Attia and Abdelrahman [4], Mokwa and Peebles [5], and Locander [6]. The gradation for RAP investigated by Attia and Abdelrahman [4] is similar to the gradation for $\mathrm{Mn} / \mathrm{DOT}$ class 5 aggregate- the same specification as the original base design for this project. As seen in Figure 6, the gradations for Mokwa and Peebles [5] and Locander [6] fall within the Mn/DOT class 7 bounds while the RAP studied by Attia and Abdelrahman [4] is finer than $\mathrm{Mn} / \mathrm{DOT}$ class 7 aggregate. Based on this comparison, the $\mathrm{Mn} / \mathrm{DOT}$ class 7 RAP used in this project is expected to have properties similar to those tested by the selected studies. Since Mn/DOT class 7 is apparently coarser than RAP studied by Attia and Abdelrahman [4], it is expected to have slightly more favorable properties as a base material, although this relationship is not studied in this paper.

The asphalt binder content of the existing pavement, prior to reclamation, was determined from a single sample analyzed using Mn/DOT Method 1852 [10], a modified version of AASHTO T 164 [11]. This laboratory analysis determined an asphalt content of $4.9 \%$ for the existing pavement. This value compares well with RAP studied by Locander [6] (4.65\% to 6.2\% asphalt content) but is greater than that studied by Attia and Abdelrahman [4] (3.6\% to 4\% asphalt content).

Several of these authors noted a binding and/or agglomeration effect where residual asphalt binder within RAP causes finer particles to adhere to each other as well as larger particles, reducing the apparent fines fraction of the RAP particle gradation. Accordingly, many of the expected properties (e.g., moisture retention, resistance to flow, and maximum dry density) of materials with a significant fines fraction are likewise reduced.

Laboratory studies of RAP appear to focus on compaction behavior and stiffness, especially resilient modulus, since these are important considerations for design and construction of pavement systems. Mokwa and Peebles [5] conclude that RAP can have lesser or greater stiffness than typical stone aggregate base material depending on the quality of RAP tested. Locander [6] concludes that RAP has stiffness and compaction properties roughly equivalent to stone aggregates routinely used for pavement base layers. Interested in these seemingly conflicting results, Attia and Abdelrahman [4] investigated the relationship between moisture content, density, and stiffness. They conclude, depending on the moisture content and dry density achieved during compaction, that the resilient modulus of $100 \%$ RAP and RAP/stone aggregate blends can be less than or greater than comparably prepared Mn/DOT class 5 aggregate base courses. They note that resilient modulus decreases with increasing moisture content during compaction, especially for samples compacted wet of optimum moisture content. Attia and Abdelrahman [4] reason that this decrease is due to a reduction in the dry density achieved during compaction and to the lubricating effect of the additional free water.

Mokwa and Peebles [5] noted that as the RAP fraction of the base layer increases, the moisture content required to achieve optimal compaction decreases. This decrease in moisture content is attributed to the relatively free-draining nature of RAP, since the agglomeration effect mentioned above tends to reduce the amount of fines available to hold water. This result is confirmed by Attia and Abdelrahman [4]. Accordingly, RAP has a relatively narrow range of comparably low-moisture contents to facilitate optimum compaction when compared to virgin stone aggregate, such as $\mathrm{Mn} / \mathrm{DOT}$ class 5 . Thus, the concern for construction articulated by the results of Attia and Abdelrahman [4] is that too much water will be added to RAP in the field, preventing compaction from achieving comparable properties and resulting pavement base performance as other aggregates. 
In the case of the project described in this paper, the field experience shows clearly that the RAP base required the continual addition of water to facilitate compaction. The quality control technician noted that the RAP drained rapidly and the surface also dried, hampering compaction efforts. With the frequent addition of water via water truck, compaction was much more effective, achieving a firm base in fewer compactor passes, passing DCP testing and exhibiting no rutting or deflection under proof rolling. After acclimating to the pace of water addition required, the paving subcontractor was able to compact the entire parking lot base course in a week with a single compactor. Compaction succeeded in producing a base condition where proof rolling exhibited only barely perceptible deflection in limited locations. As a result, all parties were pleased with the quality of the base prior to asphalt pavement placement. Furthermore, both asphalt layers were placed and compacted without incident over the entire parking lot area.

Attia and Abdelrahman [4] noted that because RAP drains freely, it is not susceptible to freeze-thaw damage (i.e., reduction in resilient modulus following a freeze-thaw cycle). They obtained this conclusion since the water inside their RAP samples was allowed to drain during the test. This observation contrasts with compaction testing, since the closed-bottom compaction molds used for compaction and resilient modulus testing would not permit the draining of water and corresponding reduction in moisture content during compaction. It appears that the observations of the parking lot construction are consistent with both the freeze-thaw finding and the compaction results since, in the field, water was able to drain from the RAP base material. Accordingly, it is very difficult under field conditions, with a properly graded subgrade, to excessively water RAP bases to the point where compaction and performance goals are not being met. Therefore, the findings of Attia and Abdelrahman [4], Mokwa and Peebles [5], and Locander [6], considered together with the field observations on this project, suggest that RAP base courses can be readily constructed with properties comparable to similarly prepared virgin stone aggregate base courses.

\section{Conclusion}

The project described in this report was successfully concluded at a cost (about \$200,000) that is significantly less than that espoused by the original cut and replace specification (about $\$ 890,000$ ) for unacceptable subgrades. The successful application of geogrid reinforcement in conjunction with the RAP base aggregate allowed the completion of the project in a timely manner with high-quality results. This design change not only continued the planned recycling of the asphalt pavement, but effectively resulted in the recycling of the entire subgrade, reducing the time, energy, and money consumed to replace it. The scrutiny of the base construction motivated by the paving subcontractor concerns about the geosynthetics allowed a number of useful, detailed observations. Specifically, observations related to the drainage and compaction behavior appear to be timely and can help to focus future laboratory studies of RAP. The original project specification substituting Mn/DOT class 7 RAP for class 5 stone aggregate appears to have been supported by the project outcomes as well as the findings of Attia and Abdelrahman [4], Mokwa and Peebles [5], and Locander [6].

The project also highlights a number of contractual issues worth considering on any project incorporating relatively new technologies, whether the technology in question is recycled materials or geosynthetics. First, risk is implied in any technical decision to reduce construction cost through the use of less conventional technology. Notions of conventional technology can be both geographically and institutionally specific. Thus, a technology does not need to be new in absolute terms to receive resistance from project participants. The apportionment of the risk and corresponding reward needs to be considered by all project stakeholders when dealing with problems such as the soft subgrade described in this paper. Second, the experience of this project suggests that the design-build framework has some efficiencies when addressing these concerns since it is possible for the prime contractor to negotiate both the design and workmanship obligations of the overall project team amongst its participants. It is also noteworthy that CFB ash could have been implemented given sufficient laboratory study. However, given the prime contractor's relative familiarity with geosynthetics and the original project schedule, geogrid reinforcement was the most competitive ground improvement option.

In conclusion, this project illustrates the successful implementation of RAP in what is rapidly becoming a commonplace application. The use of a RAP base in conjunction with geogrid reinforcement is more novel and also appears to be a complete success. Together, these technologies allowed the successful completion of the project, avoiding a significant waste of money, time, resources, and energy.

\section{Acknowledgments}

This project was funded by the 88th Regional Support Command (RSC). The author is grateful for the contributions of Josephine Newton-Lund, US Army Corps of Engineers, Kansas City District and Howard Dahlby of J. M. Waller Associates, Inc.

\section{References}

[1] Standard Specifications for Construction, Minnesota Department of Transportation, 2005.

[2] A. J. Puppala, Estimating Stiffness of Subgrade and Unbound Materials for Pavement Design, NCHRP Synthesis 382, Washington, DC, USA, 2008.

[3] AASHTO, Guide for Design of Pavement Structures, AASHTO, Washington, DC, USA, 1993.

[4] M. Attia and M. Abdelrahman, "Sensitivity of untreated reclaimed asphalt pavement to moisture, density, and freeze thaw," Journal of Materials in Civil Engineering, vol. 22, no. 12, pp. 1260-1269, 2010. 
[5] R. L. Mokwa and C. S. Peebles, "Strength, stiffness, and compressibility of RAP/aggregate blends," Pavement Mechanics and Performance, no. 154, pp. 247-255, 2008.

[6] R. Locander, "Analysis of Using Reclaimed Asphalt Pavement (RAP) as a Base Course Material," Colorado Department of Transportation-Research Report CDOT-2009-5, p. 66, 2009.

[7] ASTM, Standard Test Method for Use of the Dynamic Cone Penetrometer in Shallow Pavement Applications, ASTM, West Conshohocken, Pa, USA, 2003, D6951-03.

[8] R. M. Koerner, Designing with Geosynthetics, Prentice Hall, Upper Saddle River, NJ, USA, 5th edition, 2005.

[9] J. A. Siekmeier, D. Young, and D. Beberg, "Comparison of the Dynamic Cone Penetrometer with Other Tests During Subgrade and Granular Base Characterization in Minnesota," in Nondestructive Testing of Pavements and Backcalculation of Moduli: Third Volume, S. D. Tayabji and E. O. Likanen, Eds., American Society for Testing and Materials, West Conshohocken, Pa, USA, 1999, ASTM STP 1375.

[10] “1852: Quantitative Extraction of Bituminous Mixtures (Centrifuge)," Lab Manual, p. 7, Minnesota Department of Transportation, 2010.

[11] AASHTO, Standard Method of Test for Quantitative Extraction of Asphalt Binder from Hot Mix Asphalt (HMA), Washington, DC, USA, 2010, T 164. 

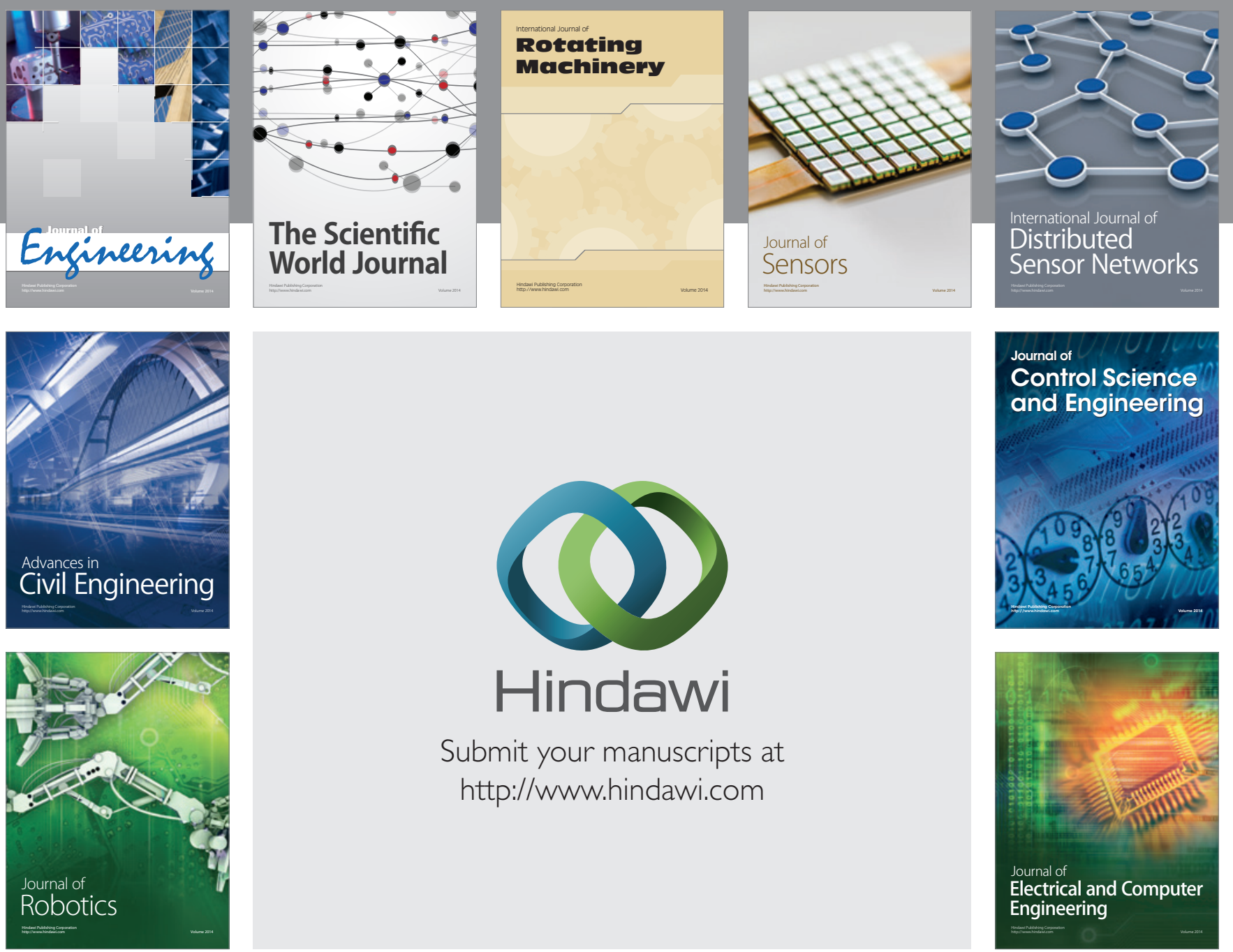

Submit your manuscripts at

http://www.hindawi.com
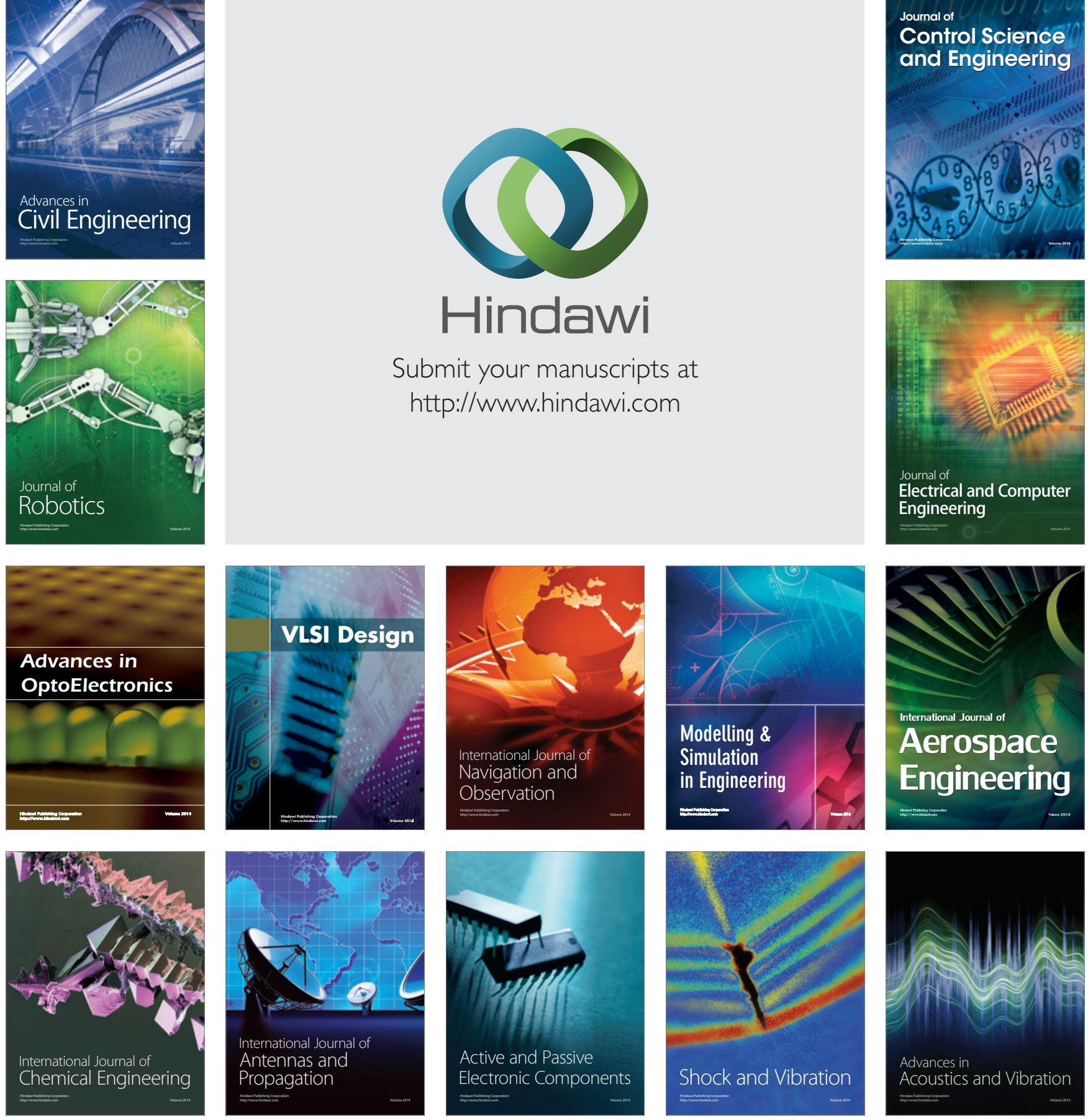